Nat. Hazards Earth Syst. Sci., 17, 925-937, 2017

https://doi.org/10.5194/nhess-17-925-2017

(C) Author(s) 2017. This work is distributed under

the Creative Commons Attribution 3.0 License.

\title{
Study on the applicability of the microtremor HVSR method to support seismic microzonation in the town of Idrija (W Slovenia)
}

\author{
Andrej Gosar ${ }^{1,2}$ \\ ${ }^{1}$ University of Ljubljana, Faculty of Natural Sciences and Engineering, Ljubljana, 1000, Slovenia \\ ${ }^{2}$ Slovenian Environment Agency, Seismology and Geology Office, Ljubljana, 1000, Slovenia \\ Correspondence to: Andrej Gosar (andrej.gosar@gov.si)
}

Received: 27 December 2016 - Discussion started: 25 January 2017

Revised: 24 April 2017 - Accepted: 21 May 2017 - Published: 21 June 2017

\begin{abstract}
The town of Idrija is located in an area with an increased seismic hazard in W Slovenia and is partly built on alluvial sediments or artificial mining and smelting deposits which can amplify seismic ground motion. There is a need to prepare a comprehensive seismic microzonation in the near future to support seismic hazard and risk assessment. To study the applicability of the microtremor horizontal-tovertical spectral ratio (HVSR) method for this purpose, 70 free-field microtremor measurements were performed in a town area of $0.8 \mathrm{~km}^{2}$ with $50-200 \mathrm{~m}$ spacing between the points. The HVSR analysis has shown that it is possible to derive the sediments' resonance frequency at 48 points. With the remaining one third of the measurements, nearly flat HVSR curves were obtained, indicating a small or negligible impedance contrast with the seismological bedrock. The isofrequency (a range of $2.5-19.5 \mathrm{~Hz}$ ) and the HVSR peak amplitude (a range of 3-6, with a few larger values) maps were prepared using the natural neighbor interpolation algorithm and compared with the geological map and the map of artificial deposits. Surprisingly no clear correlation was found between the distribution of resonance frequencies or peak amplitudes and the known extent of the supposed "soft" sediments or deposits. This can be explained by relatively well-compacted and rather stiff deposits and the complex geometry of sedimentary bodies. However, at several individual locations it was possible to correlate the shape and amplitude of the HVSR curve with the known geological structure and prominent site effects were established in different places. In given conditions (very limited free space and a high level of noise) it would be difficult to perform an active seismic refraction or MASW measurements to investigate the S-wave velocity profiles and the thickness of sed-
\end{abstract}

iments in detail, which would be representative enough for microzonation purposes. The importance of the microtremor method is therefore even greater, because it enables a direct estimation of the resonance frequency without knowing the internal structure and physical properties of the shallow subsurface. The results of this study can be directly used in analyses of the possible occurrence of soil-structure resonance of individual buildings, including important cultural heritage mining and other structures protected by UNESCO. Another application of the derived free-field isofrequency map is to support soil classification according to the recent trends in building codes and to calibrate $V_{s}$ profiles obtained from the microtremor array or geophysical measurements.

\section{Introduction}

The town of Idrija (8000 inhabitants) is an important industrial and cultural center in western Slovenia (Fig. 1a), for which the increased seismic hazard is characteristic. It is located in the relatively narrow valleys at the confluence of the rivers Nikova and Idrijca (Fig. 1b). As the oldest mining town in Slovenia, it is famous for its mercury mining tradition, going back 500 years. Part of the town is built on artificial deposits, which resulted from mining and smelting activities, or on alluvial sediments. However, the extent, thickness, and stiffness of the artificial deposits are mostly unknown because they accumulated over centuries of mining activities (Gosar and Čar, 2006). This kind of relatively soft deposit or sediment usually amplifies seismic ground motion during earthquakes; this is known as seismological site effects (Reiter, 1990). However, no seismic microzonation of the Idrija 


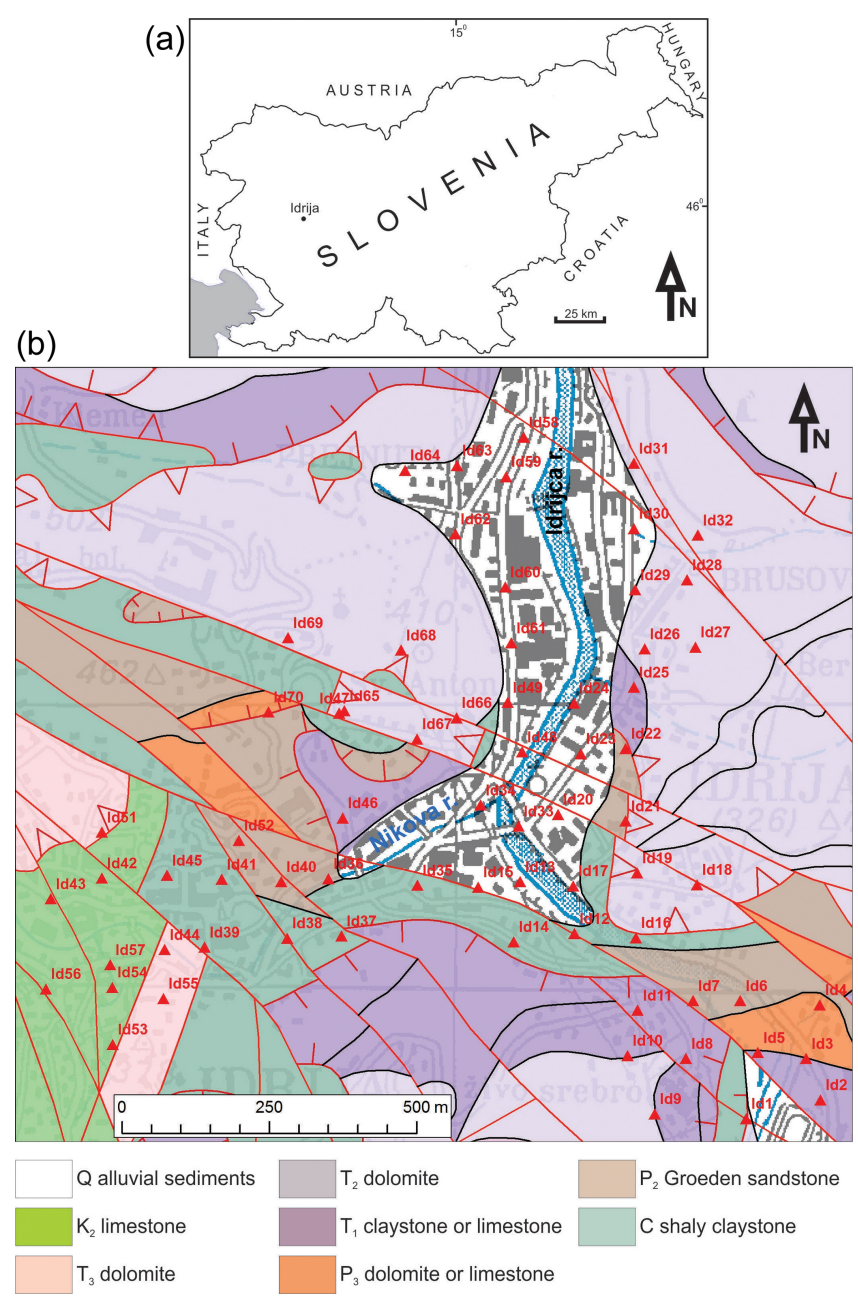

Figure 1. (a) Location of the Idrija town in Slovenia. (b) Geological map of the Idrija town area (after Mlakar and Čar, 2009). Red triangles indicate points of microtremor measurements.

urban area has been performed so far to quantitatively assess the effects of the local geological structures on seismic ground motion. There is a great necessity to prepare a comprehensive seismic microzonation in the near future to support the seismological hazard and risk assessment, as well as to provide input data for the earthquake-resistant design of buildings and structures or the retrofitting of existing buildings. This is especially important because Idrija is an important local center, undergoing fast development. It is also a UNESCO World Heritage Site, so it is crucial to protect the industrial and cultural heritage buildings and structures related to 500 years of mercury mining from all kinds of natural disasters, including the seismic hazard.

Methodologies used in seismic microzonation have been significantly improved in the last 2 decades through better understanding of seismological site effects, the development of new research methods for characterization of the shallow subsurface, and through preparation of appropriate standards and guidelines (Ansal, 2004). Seismic microzonation is usually performed at different levels, from a preparatory level (level 1), which is based on existing data, through intermediate level (level 2), in which simplified methods and empirical laws are used to assess ground motion amplification, to the highest level (level 3), which involves advanced methods for quantitative characterization of the sediments and the application of numerical methods to derive amplification factors (Bramerini et al., 2015). Level 3 seismic microzonation provides input data for state-of-the-art earthquakeresistant design or retrofitting. Among other geophysical and geotechnical methods used for level 3 microzonation, the seismological microtremor horizontal-to-vertical spectral ratio (HVSR) method has achieved high recognition in the last decade because it provides very important data on the main resonance frequency of soft sediments overlaying stiff geological bedrock (Bard, 1999). The results of the freefield microtremor measurements are thus used in different soil classification standards and are especially valuable when compared with additional microtremor measurements inside buildings to assess the danger of soil-structure resonance, which can significantly enhance the damage during earthquakes (Gallipoli et al., 2004). They are also used to constrain the S-wave velocity-depth profiles obtained from the microtremor array or MASW measurements through a joint modeling of HVSR and dispersion curves.

The microtremor HVSR method has gained great popularity also because it provides the sediments' resonant frequency without knowing the thickness of sediments and their vertical $\mathrm{S}$-wave velocity profile, the data that are otherwise needed to numerically calculate the frequency. However, these data can be acquired only with relatively expensive geophysical investigations like seismic refraction, MASW methods, or drilling. In contrast, the microtremor method provides results only when there is a relatively strong impedance contrast between sediments and the bedrock (Ansal, 2004). If the knowledge on the sediments and bedrock physical properties is insufficient, the method should be first tested to prove that it is effective in given geological conditions. This is especially important in case of very heterogeneous geological settings, like in Idrija. This paper presents a study on the applicability of the microtremor HVSR method in the Idrija area in order to evaluate this method and its possible contribution to the future seismic microzonations. A high-level seismic microzonation of the Idrija region is needed to support urban planning, earthquake-resistant design, the protection of industrial and cultural heritage buildings and structures, and civil protection emergency planning. However, no data on the S-wave velocity structure of sediments and bedrock were collected so far using alternative methods (microtremor array methods, MASW, seismic refraction, or velocity measurements in boreholes) to support seismic microzonation. This increased the motivation for a study based on the microtremor HVSR method because no prior information on the velocity struc- 
ture is needed to interpret the results. Moreover, recommendable future alternative investigations of the velocity structure using more expensive methods could be more efficiently planned based on the microtremor HVSR results. Nevertheless, it should be kept in mind that microtremor HVSR investigations are only the first step in a complete microzonation study.

The geological setting in the Idrija area (Fig. 1b) is rather complex (Čar, 2010). The largest part of the area is built of Triassic dolomite, limestone, and claystone. In-between are Carboniferous claystones and Permian sandstones, dolomite, or limestone. Upper Cretaceous limestone is present only in the SW part of investigated area (Mlakar and Čar, 2009). All these lithological units are considered as a rock according to seismic soil classifications like Eurocode 8 (Ansal, 2004). The region is cut by several faults which extend mainly in the NW-SE direction, parallel to the major dextral strike-slip Idrija fault. Fault zones can be several tens of meters in width (Čar and Gosar, 2011) and the rocks inside these zones are highly fractured or exposed to pronounced weathering, especially in the case of claystones. Highly fractured rock can locally influence the impedance contrast between the bedrock and overburden sediments.

Quaternary alluvial sediments extend along both sides of the Idrijca river and in the lower part of the Nikova river (Fig. 1b). They are composed of gravel and clay, which can generally be classified as soil type B or C according to the Eurocode 8 standard. However, the scale of the map $(1: 25000)$ prepared by Mlakar and Čar (2009) does not allow us to show the details of the soft sediments in the town area. Unfortunately, no detailed maps or cross sections of alluvial sediments have been prepared so far for the town area to support seismic microzonation, due to the lack of geotechnical drilling and geophysical investigations. From the topography of the Idrijca and Nikova valleys it is reasonable to expect that the thickness of alluvial sediments does not exceed $15 \mathrm{~m}$. A more or less thick layer of weathered or highly fractured rock and thin alluvium can also be expected in other places. Another soft "sediment", up to $10 \mathrm{~m}$ thick, is related to the mining and smelting deposits accumulated during centuries of mining activities (Fig. 2). Their extent roughly corresponds to the extent of Quaternary alluvial sediments (Fig. 1b), building a situation which can make a seismic response quite complex. These artificial deposits can also be classified according to their general characteristics as soil type $\mathrm{B}$ or $\mathrm{C}$ according to Eurocode 8. However, since no applied geophysical (seismic refraction or MASW) or seismic borehole investigations were performed in the area to determine the $\mathrm{S}$-wave velocity structure of the sediments, classification based on quantitative parameters is impossible.

Due to complex geological setting in Idrija, characterized by a heterogeneous bedrock which is both highly fractured and weathered, as well as overlain with alluvial and artificial deposits, no simple relation is expected between the extent, the homogeneity, and the thickness of the supposedly

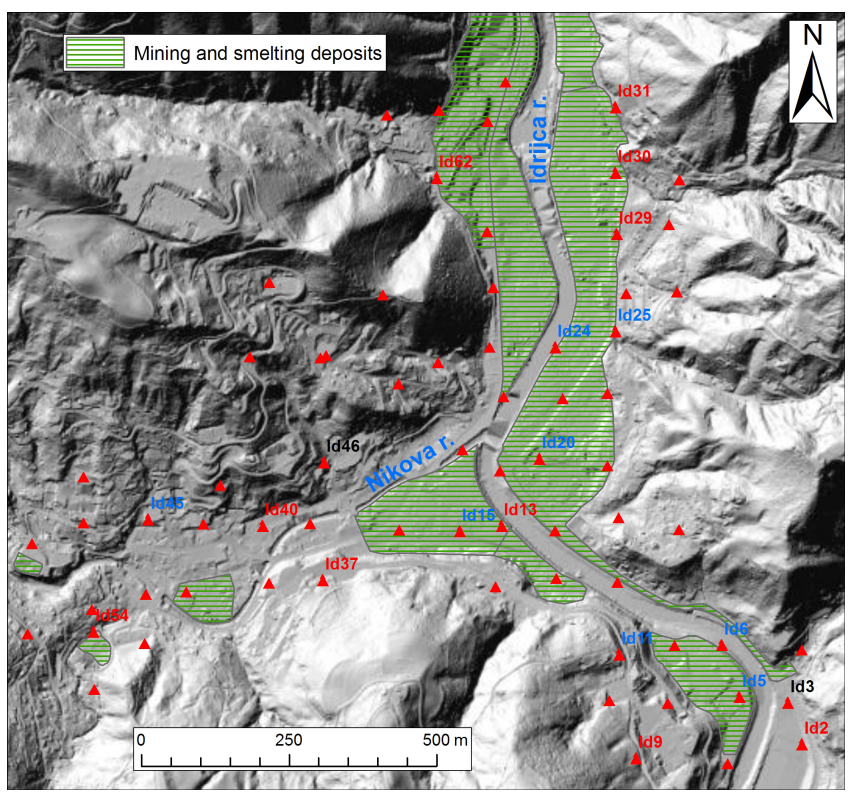

Figure 2. Position map of microtremor measurements (red triangles) in the Idrija town area. Red labeled points indicate examples of HVSR analyses shown in Fig. 5, blue labeled points examples shown in Fig. 6, and black labeled points examples shown in Figs. 3 and 4. Extent of mining and smelting deposits is shown (data provided by Idrija municipality). Basemap shaded relief was derived from lidar $1 \mathrm{~m}$ resolution digital elevation model (Ministry of the Environment and Spatial Planning, portal e-Vode).

soft sediments and seismic site amplification. The application of advanced quantitative investigation methods is crucial to support any microzonation studies in the area. Since microtremor HVSR studies were so far mainly performed in sedimentary basins of rather regular shape, where the relation between the thickness of sediments and the resonance frequency is more straightforward, any study performed in a more complex geological setting is of wider scientific interest and contributes to the verification of the methodology.

\section{Seismic hazard in the Idrija area}

According to the official seismic hazard map of Slovenia for the 475-year return period (Lapajne et al., 2001), the Idrija area is in the $0.200 \mathrm{~g}$ peak ground acceleration zone but not far $(8 \mathrm{~km})$ from the border with the $0.225 \mathrm{~g}$ zone. Since the highest seismic hazard is $0.250 \mathrm{~g}$ in the central and utmost NW Slovenia, the Idrija area can be considered as having a relatively high seismic hazard. The main question with the seismic hazard assessment in this area is the exact location of the strongest known historical earthquake in Slovenia, which occurred in 1511 and had the estimated magnitude of 6.8 . It is supposed that it occurred in the Alps-Dinarides junction area somewhere in the W Slovenia, but the exact location and mechanism of this event are still debated (Fitzko et 
al., 2005). However, this earthquake is often referred to as the Idrija earthquake because 500 years ago there were only a few stone buildings (castles, churches, etc.) in W Slovenia and only sparse records on their earthquake damage are available in historical documents (Košir and Cecić, 2011). This makes it difficult to evaluate the macroseismic field, which is crucial to constrain the epicenter location and the magnitude of the event. However, the Idrija mercury mine started its operation in 1495, a decade before the earthquake. Although there were only two stone houses (others were made from wood) at the time in Idrija (the church and the mining inspector's home), there is some secondary evidence of the damage (Košir and Cecić, 2011). The most significant was the huge landslide downstream from Idrija, which completely buried the Idrijca river. As a consequence a lake was formed, submerging the whole mine as well as part of the town. It took 7 years to retrofit the mine and enable its further operation. Another reason for naming the 1511 event as the Idrija earthquake is the fact that the Idrija fault is the most important dextral strike-slip Dinaric fault in W Slovenia (Moulin et al., 2014). Idrija is located approximately in the middle of its total length of $120 \mathrm{~km}$. Detailed geomorphological, structuralgeological, and paleoseismological studies revealed that it has the potential to generate strong earthquakes (Moulin et al., 2016), although its recent seismicity (in the last century) is rather low (Živčić et al., 2011).

In the old official seismic hazard map of Slovenia showing the Medvedev-Sponheuer-Karnik (MSK) intensities for 500-year return period (Ribarič, 1987), the supposed location of the 1511 earthquake had a great influence on the distribution of zones with the highest seismic hazard. According to this map, Idrija is located in an intensity VIII MSK zone, but the intensity IX MSK zone begins $10 \mathrm{~km}$ to the north. It is obvious that such a distribution of high-intensity zones is controlled only by the 1511 event, listed in the applied seismic catalogue at coordinates that are very poorly constrained, because no other strong historical earthquakes are known in this area. Although intensity seismic hazard maps are no longer used in engineering design (they have been replaced by peak ground acceleration maps), a new intensity map for 475-year return period was prepared in 2011 to be used in civil protection for emergency planning (Šket Motnikar and Zupančič, 2011). According to this map, which is much smoother than the Ribarič (1987) map, Idrija is located in the VIII EMS98 (European Macroseismic Scale) zone and there is no IX EMS-98 intensity zone in the vicinity.

In conclusion, according to all existing seismic hazard maps of Slovenia for 475- or 500-year return periods, Idrija is located in relatively high seismic hazard zones: $0.200 \mathrm{~g}$ peak ground acceleration, VIII MSK, or VIII EMS-98. It is therefore essential to prepare a comprehensive seismic microzonation map for the Idrija area to enable thorough urban planning, earthquake-resistant design of buildings, protection of heritage buildings or structures, and emergency planning.

\section{Methodology}

The microtremor method has been widely used for site effect studies in the last decade (Bard, 1999), although the theoretical basis of the HVSR analyses of the free-field microtremor measurements is still debated. Different theories on the content of body and surface waves in microtremors have been considered. More widely accepted is the "surface waves" explanation (Bard, 1999; Bonnefoy-Claudet et al., 2006), by which the HVSR is related to the ellipticity of Rayleigh waves, which is frequency dependent. The HVSR therefore exhibits a sharp peak at the fundamental frequency of the sediments, when there is a high impedance contrast between the sediments and underlying bedrock. Criticism of the HVSR method was often related to the fact that there is no common practice for data acquisition and processing (Mucciarelli and Gallipoli, 2001) but some standards were provided later (SESAME, 2004). Today it is widely accepted that the frequency of the HVSR peak reflects the main resonance frequency of the sediments. The main advantages of the HVSR method are relatively simple, low-cost measurements and a straightforward estimate of the resonance frequency of sediments without previous knowledge of the geological and S-wave velocity structure of the subsurface. This frequency can be used directly to assess the danger of soilstructure resonance or independently, because there is a trend to consider also the resonance frequency or the period of the sedimentary cover in different soil classifications for seismic microzonation (e.g. Ansal, 2004; Luzi et al., 2011). The use of microtremors was later extended to study the dynamic parameters of buildings, for instance to identify their fundamental frequencies (Mucciarelli et al., 2001; Gallipoli et al., 2004; Boutin and Hans, 2008; Gosar et al., 2010).

\section{Microtremor measurements}

Microtremor measurements were performed in an area of approximately $0.8 \mathrm{~km}^{2}$ which extends across the whole urban area of Idrija on both sides of the Idrijca and Nikova rivers (Figs. $1 b$ and 2). Seventy measurements were conducted altogether, with a spacing of $50-200 \mathrm{~m}$ between measuring points. The locations were carefully selected to avoid the influence of buildings, industrial facilities, and traffic as much as possible, although this was not always possible in the urban environment. The grid of measuring points is therefore quite irregular. The free-field space between houses in the town center was very limited, while the selection of measurement points in the industrial northern part was limited due to the restricted access to some industrial facilities.

Measurements were performed with two Tromino seismographs (Micromed, 2005) composed of three orthogonal electrodynamic velocity sensors, a GPS receiver, digitizer, and a recording unit with a flash memory card. All parts are integrated in a common case to avoid electronic and me- 
chanical noise, which can be introduced by the wiring between equipment parts. Good ground coupling on soft soil was obtained by using long spikes mounted at the base of the seismograph. The sampling frequency was $128 \mathrm{~Hz}$ and the recording length at each point was $20 \mathrm{~min}$. The experimental conditions of microtremor measurements (e.g. Chatelain et al., 2008) were mainly favorable. The main difficulties arose from the low-frequency traffic and industrial noise.

The HVSR analysis was performed in the following way. The recorded time series were visually inspected to identify possible erroneous measurements and stronger transient noise. Each record was then split into $30 \mathrm{~s}$ non-overlapping windows, for which amplitude spectra in the range of $0.1-$ $64 \mathrm{~Hz}$ were computed using a triangular window with $5 \%$ smoothing and corrected for the sensor transfer function. Different levels of smoothing were tested, but $5 \%$ gave the best results. The HVSR was computed as the geometric average of both horizontal component spectra divided by the vertical spectrum for each window. Finally, the average HVSR function of all windows with the corresponding $95 \%$ confidence interval was computed. To understand the more complex HVSR results with several peaks, the Fourier amplitude spectral curves (example in Fig. 3a) were analyzed, which usually allows a clearer recognition of spurious peaks. An example of the HVSR analysis for a measurement at point Id46 is shown in Fig. 3. Fourier amplitude spectral curves (Fig. 3a) show a clear difference between both horizontal and the vertical component in a narrow frequency range. This difference results in a clear peak on the HVSR curve at $12.3 \mathrm{~Hz}$ with an amplitude of 4.2 (Fig. 3b). The stability of the H / V spectral ratio within a 20 min recording was analyzed in $30 \mathrm{~s}$ windows, as shown in Fig. 4 for a measurement at point Id3. From the color-coded plot of HVSR functions for all windows (Fig. 4a), the windows, including strong transient lowfrequency noise, were identified and excluded from further computation (Fig. 4c). After the removal of the noisy parts of the record, the signal-to-noise ratio improved in comparison to the original HVSR curve (Fig. 4b), narrowing the $95 \%$ confidence interval, especially in the low-frequency part of the spectral ratio (Fig. 4d). A very clear and pronounced peak was obtained at $9.4 \mathrm{~Hz}$ with a HVSR amplitude of 9.3. For most of the measurements it was sufficient to exclude two to eight windows (each $30 \mathrm{~s}$ long) from further computation, i.e. $5-20 \%$ of the whole record length. However, in some locations the low-frequency noise was very high and persistent. In this case measurements were repeated at another time and the results compared. The temporal stability of the $\mathrm{H} / \mathrm{V}$ spectral ratio was generally good after the exclusion of the noisiest windows. This is reflected in a relatively narrow $95 \%$ confidence interval for average HVSR functions which was obtained for most of the records (examples shown in Fig. 5). However, there were some locations (for example Id5 on Fig. 6) with persistent low-frequency noise, both in the original and the repeated measurements. The temporal stability of the $\mathrm{H} / \mathrm{V}$ spectral ratio was low in this case and could preclude the determination of the resonance frequency. However, this problem was more pronounced at low frequencies below $1 \mathrm{~Hz}$, which are generally below the frequency range of engineering interest for low-rise buildings which prevail in Idrija.

\section{Results of the microtremor HVSR analyses}

The HVSR analyses of free-field measurements showed that most of them (Fig. 5) fulfil the criteria for reliable measurements and clear peaks (SESAME, 2004). If a sufficient number of criteria are fulfilled, the frequency of the peak is considered to be the fundamental frequency of the sediments down to the first strong impedance contrast. The main reasons for the failure of the above criteria are (a) a high level of low-frequency noise during the whole $20 \mathrm{~min}$ of recording, (b) several peaks in a spectrum, or (c) a flat spectral ratio. In cases where the small amplitude of the HVSR peak caused the failure of the criteria for a clear peak, the results were compared with adjacent measurements. If the frequencies of questionable peaks were comparable with the frequencies obtained at adjacent points, they were included in the database. In the end, it was possible to reliably define the peak frequency for 48 measuring points out of 70 .

Several examples of the HVSR graphs are shown in Figs. 5 and 6 . The locations of these measurements are shown in Figs. $1 \mathrm{~b}$ and 2. In approximately one third of the measurements, very clear peaks were obtained showing the broad range of fundamental frequencies between 2.5 and $19.5 \mathrm{~Hz}$. The temporal stability of the signal was moderate. In general, the $95 \%$ confidence interval of averaged curves is narrower at higher frequencies and wider at lower frequencies. This is mainly due to the low-frequency industrial and traffic noise, which could not be completely removed by exclusion of windows with stronger transients. In some cases there is a sharp peak in the HVSR curve (Id2, Id37, Id54, and Id62 in Fig. 5) which is rather symmetrical and has a relatively large amplitude (5-7) and a narrow $95 \%$ confidence interval. Such results are most desirable for the derivation of the sediments' resonant frequency. However, they reflect the highest impedance contrast between sediments and the bedrock and thus the highest amplification of the seismic ground motion. Asymmetric shapes of HVSR curves with additional side peaks, which have slightly lower amplitudes, are also common (Id13, Id30, and Id40 in Fig. 5). In most cases, the side peaks were recognized as spurious peaks resulting from industrial noise. It is generally possible to reliably determine the sediments' resonance frequency even if some criteria for a clear peak (SESAME, 2004) are not fulfilled. In some other cases the amplitude of the second peak has a similar (Id9 in Fig. 5) or even higher amplitude (Id31 in Fig. 5) than the supposed main peak. However, these additional peaks occur at very high frequencies $(26 \mathrm{~Hz}$ in Id9 and $48 \mathrm{~Hz}$ in Id31) and cannot reflect the layers of seismological 

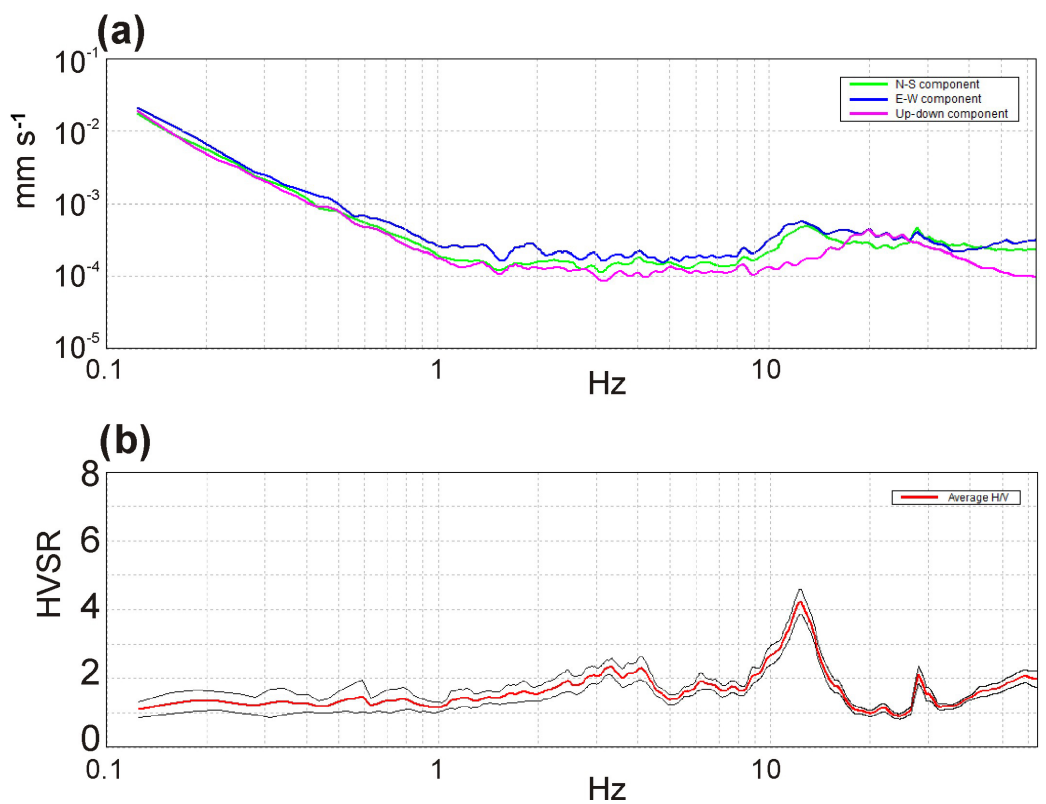

Figure 3. An example of microtremor horizontal-to-vertical spectral ratio (HVSR) analysis at point Id46. (a) Three amplitude spectral curves clearly shows the difference between both horizontal (N-S, E-W) and the vertical (up-down) component in a narrow frequency range. (b) Observed difference results in a clear peak on the HVSR curve at $12.3 \mathrm{~Hz}$. Thin lines represent the $95 \%$ confidence interval.

interest, because they are very thin. It is even possible that some of these high-frequency peaks are artifacts of the very noisy (monochromatic) conditions. The frequency at which the main peak occurs is therefore still a reliable estimate of the sediments' resonance frequency. In some cases the level of low-frequency noise was rather high, which resulted in a wide $95 \%$ confidence interval at frequencies below $5 \mathrm{~Hz}$ (Id9 and Id40 in Fig. 5). In a few cases (Id29 in Fig. 5) the $95 \%$ confidence interval is relatively wide in the whole spectral range and reflects very noisy measurement conditions in a wide range of frequencies. The stability of the $\mathrm{H} / \mathrm{V}$ spectral ratio was therefore lower and, if the noise was persistent during the whole $20 \mathrm{~min}$ record, it was not possible to improve the signal-to-noise ratio by excluding the noisy windows as shown in Fig. 4.

Figure 6 shows several examples of more complex HVSR curves and examples with a flat response. Among the complex HVSR curves, examples with several peaks of similar amplitudes in the spectral range of seismological and earthquake engineering interest are more problematic for interpretation. At point Id6 (Fig. 6) there are four peaks with the amplitude of 3-4 in the frequency range of 6-14 Hz, which are not well separated. Although there are no clear indications in the Fourier spectra, some of them are most probably spurious peaks resulting from the high level of artificial noise in the town center. The additional factor which can have impact on the shape of the HVSR curve can be the multilayer setting above the bedrock which includes alluvial sediments and mining deposits on the left bank of the Idrijca river (Fig. 2). However, impedance contrasts between alluvial and artificial layers seem to be relatively low. At point Id11 (Fig. 6) there is a series of peaks in the frequency range of $9-20 \mathrm{~Hz}$ as well as a separate peak at $2.5 \mathrm{~Hz}$. This can indicate a thin layer of sediments, complex topography (shown in Fig. 2), and probably another deeper geological interface. The measurement at point Id20 (Fig. 6) is also interesting, showing a clear, broad, and high-amplitude peak at around $4 \mathrm{~Hz}$, on top of which are two small and narrow peaks with a similar amplitude of around 6.5. Although high amplitudes indicate a large impedance contrast at locations with relatively thick mining deposits (Fig. 2), it is impossible to isolate only one frequency for eventual soil-structure resonance analysis. A broader frequency range of $3-6 \mathrm{~Hz}$ should be considered. For the measurement Id24 (Fig. 6) three low-amplitude (3.0-3.5) peaks are characteristic in the frequency range of $6-12 \mathrm{~Hz}$, showing again the presence of spurious peaks and perhaps also the influence of both alluvial and mining deposits present at this point, which is located on the right bank of the Idrijca river (Figs. $1 \mathrm{~b}$ and 2).

There were approximately 10 measurements for which an almost flat $\mathrm{H} / \mathrm{V}$ spectral ratio was obtained. In theory this means no soft sediments or only a small impedance contrast between the sediments and the bedrock. Consequently, zero or very small amplification of seismic ground motion can be expected, which is a favorable condition in seismic microzonation. In the given geological setting it was interesting to analyze whether such conditions are characteristic only for locations far from the valley floor filled with alluvial and mining deposits, where the bedrock is supposed to lie right under the surface. However, for the three ex- 

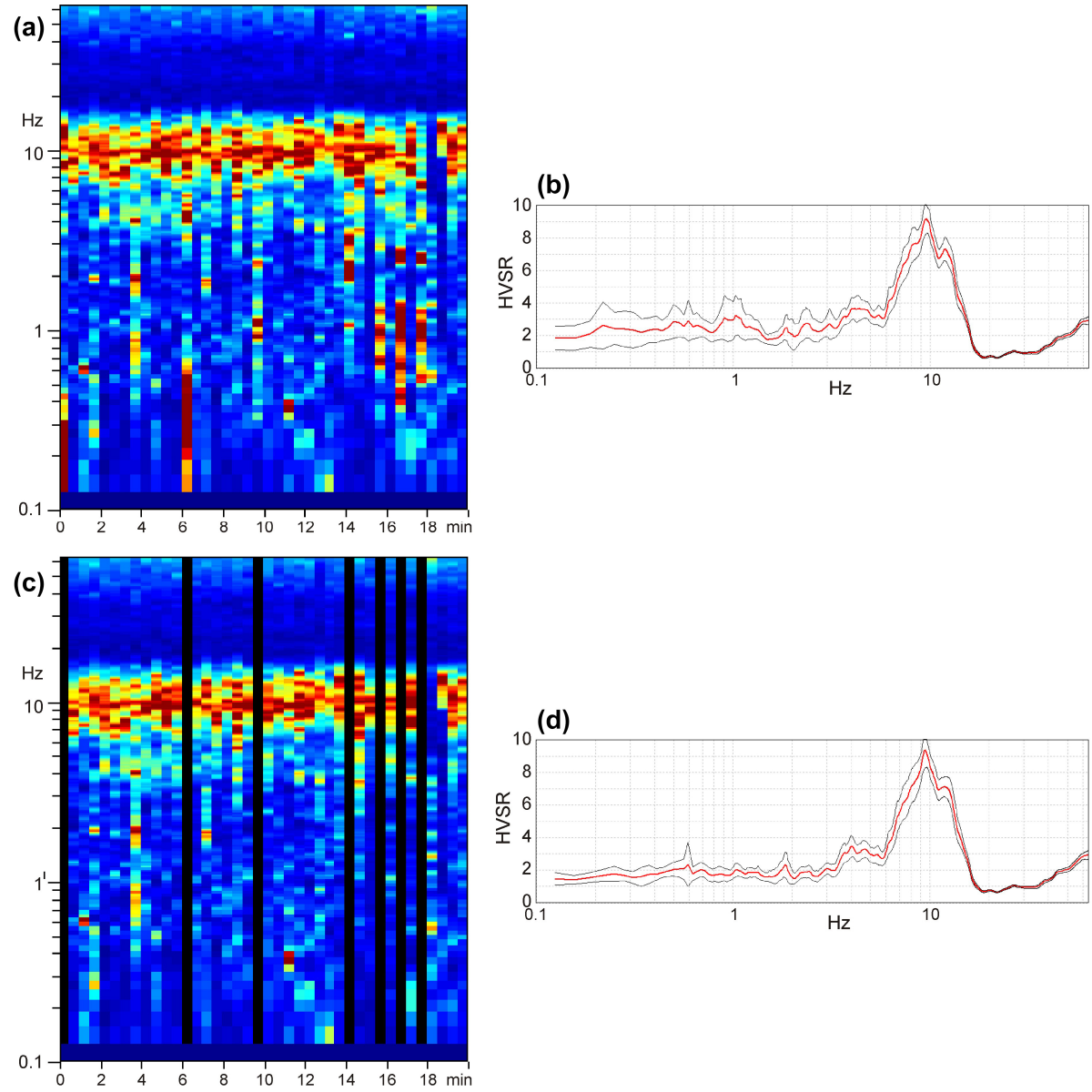

Figure 4. (a) Stability of the $\mathrm{H} / \mathrm{V}$ spectral ratio within $20 \mathrm{~min}$ long record at point Id 3 analyzed in $30 \mathrm{~s}$ long windows. (b) Corresponding average HVSR curve for all windows. (c) Removal of several noisy windows from the record resulted in (d) better signal-to-noise ratio in HVSR curve.

amples shown in Fig. 6, it is clear that they reflect different geological conditions. Measurement Id15 is located in the middle of mining deposits (Fig. 2), but perhaps out of the extent of alluvial deposits. This could indicate that old mining and smelting deposits could be very well compacted, reducing the impedance contrast with the bedrock. In contrast, point Id 25 is located on the bedrock outside of mining and alluvial deposits (Fig. 2) and thus logically does not show any impedance contrast. Measuring point Id45 is located in the W part of the town (Fig. 2) at a location where only a thin weathered layer or colluvium is expected. In a few cases the measurements were dominated by a prominent low-frequency noise, which is reflected in high amplitudes in the $\mathrm{H} / \mathrm{V}$ spectral ratio at frequencies below $1 \mathrm{~Hz}$ (Id5 in Fig. 6). This is usually not an indication of a very deep impedance contrast but is rather an artifact of the poor stability of the three-component microtremor record at low frequencies, which could not be avoided by the exclusion of high-noise windows from the HVSR computation because it persisted through the whole measurement. Since the re- sponse in the frequency range of engineering interest (1$15 \mathrm{~Hz}$ ) is low, such measurements (Id5 in Fig. 6) can also be considered as flat response.

In addition to the analyses based on different characteristics of HVSR curves, the results were also compared based on the lithology. It would be incredibly interesting to analyze the possible difference in the HVSR response between alluvial and mining deposits, but this was impossible as mining deposits lie over the whole known extent of the alluvial deposits (Figs. $1 \mathrm{~b}$ and 2) with the exception of points Id2 and Id3 in the SE part. However, the thickness of both deposits can vary considerably from place to place, so it is only possible to study the combined layers' influence on the HVSR curves. The two points located directly on alluvial deposits (Id2 in Fig. 5 and Id3 in Fig. 4) show very clear peaks at a relatively high frequency $(8.7$ and $9.4 \mathrm{~Hz}$ respectively), indicating thin alluvium. The corresponding peak amplitude is 5.7 and 9.3 respectively, indicating a high impedance contrast with the Triassic claystone or limestone in the bedrock. The measuring points located on mining deposits have a more 

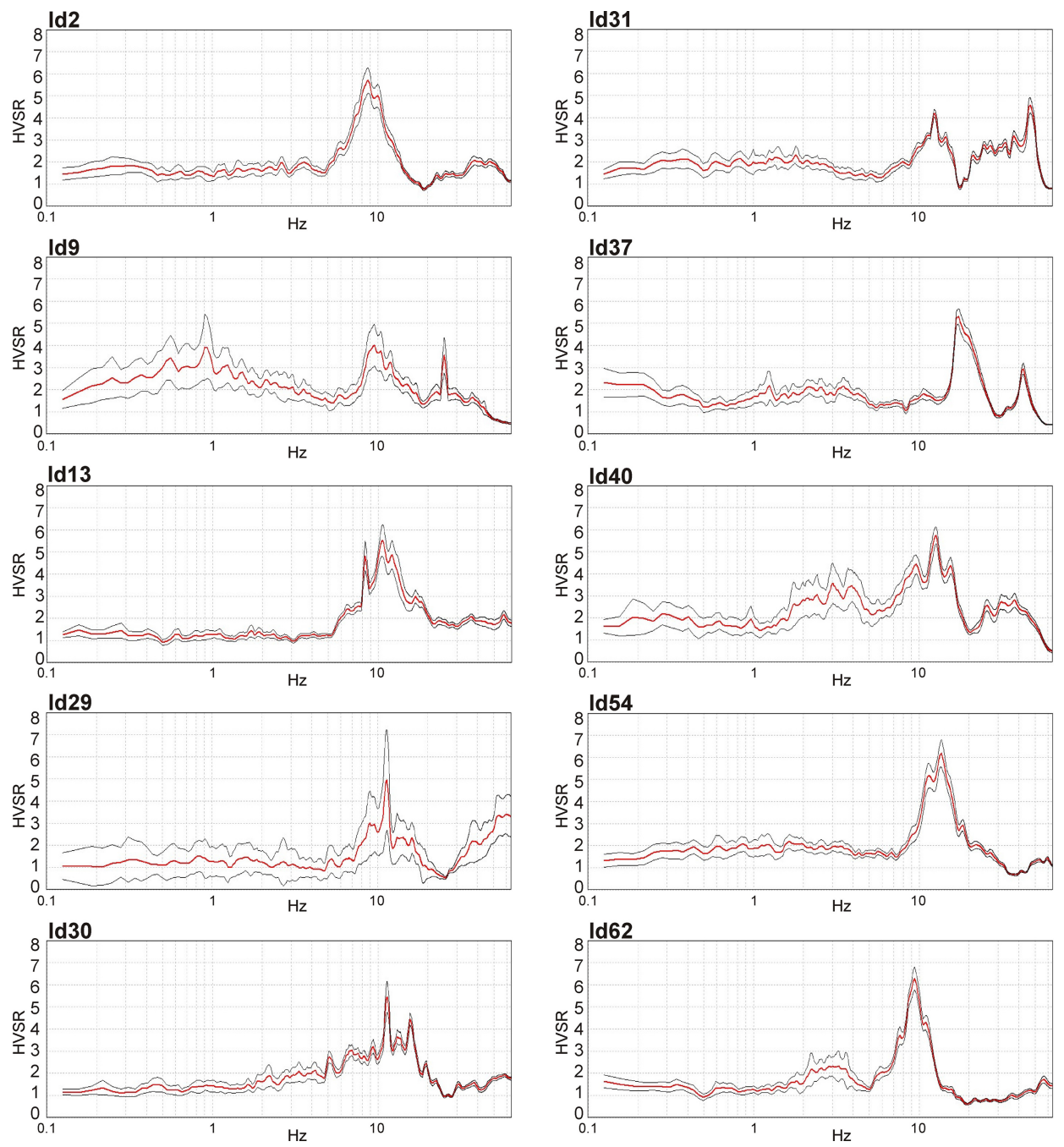

Figure 5. Examples of microtremor measurements on points where a clear HVSR response was obtained. Locations of measurements are shown in Fig. 2. Thin lines represent the $95 \%$ confidence interval.

heterogeneous HVSR response, which could be related to the expected thickness supposed from the location. Points Id29, Id30, Id31, and Id25 are all located near the edge of mining deposits. Very high peak frequencies were obtained $(11.4,11.3$, and $12.4 \mathrm{~Hz})$, as well as a flat response (Id25) at a point located probably just outside the deposit on the Triassic bedrock. More surprising are the results from the central part of the mining deposits where a complex, but a clear peak was obtained for point Id20 (Fig. 6) with a low frequency $(3.4 \mathrm{~Hz})$, indicating a greater thickness of mining and alluvial deposits and a strong impedance contrast with the Triassic bedrock. In contrast, the HVSR amplitude at points Id15 and Id24 (Fig. 6) is much lower. This indicates that the stiffness and density of artificial deposits, which were deposited through centuries of mining activity, can vary laterally considerably. The case of point Id54 is especially interesting: it is located in the $\mathrm{W}$ part of the town on a small patch of mining deposits, where a very clear HVSR peak (Fig. 5) at the frequency of $16.2 \mathrm{~Hz}$ and the amplitude of 7.2 indicates a very thin deposit and a high impedance contrast with the Cretaceous limestone in the bedrock. For the measuring points which are located directly on the bedrock outside the known extent of alluvial and mining deposits, a flat response was obtained in general (for example Id45 in Fig. 6) or a peak at a very high frequency $(17.2 \mathrm{~Hz}$ for $\operatorname{Id} 37$ and $12.6 \mathrm{~Hz}$ for Id40 in Fig. 5), indicating a very thin weathered layer on the Carboniferous claystone or Permian sandstone. These analyses showed that in the Idrija area, for a number of reasons, there is no simple correlation between the extent of supposed "soft" sediments and the seismic response reflected in microtremor HVSR curves. This can be explained by lateral heterogeneities in the compaction and stiffness of deposits as well as the complex geometry of sedimentary bodies. However, based on the obtained frequencies and amplitudes of the HVSR peaks, prominent site effects can be expected at dif- 

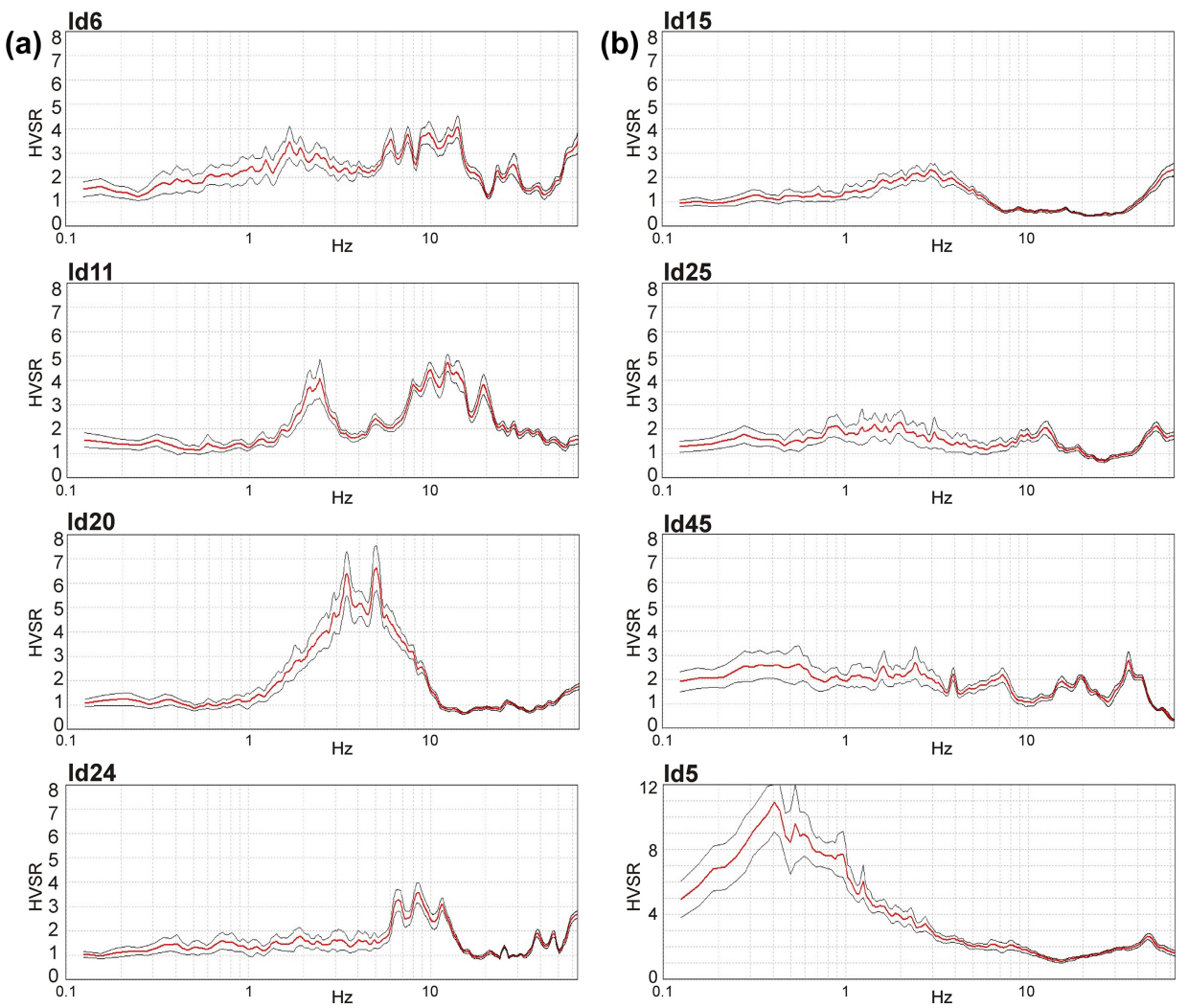

Figure 6. (a) Examples of microtremor measurements with several peaks in HVSR curve. (b) Examples of microtremor measurements with no HVSR response or pronounced low-frequency noise (Id5). Locations of measurements are shown in Fig. 2. Thin lines represent the $95 \%$ confidence interval.

ferent places, increasing the importance of the application of the microtremor method.

\section{Isofrequency and HVSR peak amplitude maps}

The distribution of established frequencies for 48 measuring points with a sufficient HVSR response using $2 \mathrm{~Hz}$ wide intervals is shown in Fig. 7. From this graph it is clear that there is no systematic distribution of frequencies, which is usually observed in sedimentary basins with rather symmetrical shape. In such conditions the distribution of frequencies reflects the gradual thickening of the sediments towards the center of the basin or buried valley. In contrast, in the Idrija area there is obviously no simple relation between the topography of the Idrijca and Nikova river floors and the established soft sediments' resonance frequencies. This means that there are no uniform bodies of alluvial sediments along either of the rivers and that sediment thicknesses and physical properties can vary considerably within short distances. Such conditions are a challenge for any seismic microzonation because it is difficult to interpolate or extrapolate the data obtained at sparse discrete points in the study area (for instance by drilling).

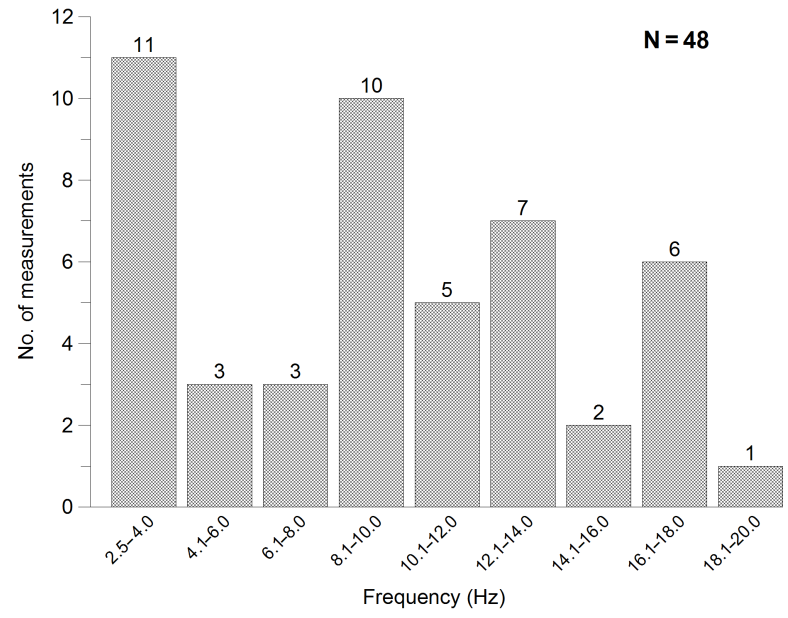

Figure 7. Distribution of sediments main frequency derived from microtremor HVSR analysis at 48 points with sufficient response.

The data from 48 measuring points were used to prepare the isofrequency map showing the resonance frequencies of sediments (Fig. 8). The map was drawn using the natural neighbor interpolation algorithm. The fundamental frequency of sediments shows a distribution in the range of 
$2.5-19.5 \mathrm{~Hz}$. The areas in the $\mathrm{S}$ and $\mathrm{E}$ parts with no data or with a flat HVSR response were excluded from contouring the map. Although the frequencies above $12 \mathrm{~Hz}$ are not of engineering interest because they are attributable to a very thin sediment layer, they were kept in the database to support correct interpolation, as some very clear peaks were obtained at high frequencies (for example Id37 and Id54 in Fig. 5). Those peaks cannot be considered as flat responses since the points with no frequency value cannot be used in contouring the map. Very high frequencies (above $16 \mathrm{~Hz}$ ) are limited to small areas located on the slopes of the valleys where only a very thin layer of soft sediments or weathered material lies on top of the stiff bedrock. The largest high-frequency area is in the S part of the town and extends in a W-E direction. In the $\mathrm{N}$ part there are two small high-frequency areas on both sides of the Idrijca river, high above the river floor where the bedrock is very shallow. Surprisingly, the lowest observed frequencies $(2.5-4.0 \mathrm{~Hz})$, which were established at many (11) points (Fig. 7), do not extend along the rivers, where the thickest layer of alluvial sediments is expected, but in the central part of investigated area, extending in a W-E direction across both rivers (Fig. 8). There is also no correlation between the low-frequency area and the extent of mining and smelting deposits. The majority of the surveyed area is characterized by relatively high frequencies in the range of $8.0-14.0 \mathrm{~Hz}$, including both river banks and areas with artificial deposits. This indicates that the sediments or deposits are relatively thin and/or well compacted.

The HVSR peak amplitudes map is shown in Fig. 9. The amplitudes of microtremor HVSR peaks are mainly in the range of 3-6; they reach higher values in rare cases. The amplitude of the peak is related to the impedance contrast between sediments and the bedrock, but in principle it cannot be used for quantitative estimation of this contrast or site amplification (SESAME, 2004). There is no visible correlation between a certain frequency range (Fig. 8) and the distribution of higher or lower peak amplitudes (Fig. 9), with the extent of either alluvial sediments or artificial deposits.

Comparing both maps derived from microtremor HVSR measurements (Figs. 8 and 9) with the geological map (Fig. 1b) and the distribution of mining and smelting deposits in the Idrija area (Fig. 2) shows that there is no clear relation to the extent of the sediments that are usually characterized as "soft" in seismic microzonation. In such conditions, a very extensive program of geophysical investigations (and/or drilling) using seismic refraction and MASW methods, for example, will be needed to derive S-wave velocity profiles and the depth down to the "seismological" bedrock and numerically calculate the site amplification and resonance frequency in the town area. To some extent, the microtremor HVSR method has an advantage, because it provides the sediments' main resonance frequency without the knowledge of the $\mathrm{S}$-wave velocity profiles and their thickness. The isofrequency map can also be used to directly assess the danger of soil-structure resonance. Recently, a large number of ma-

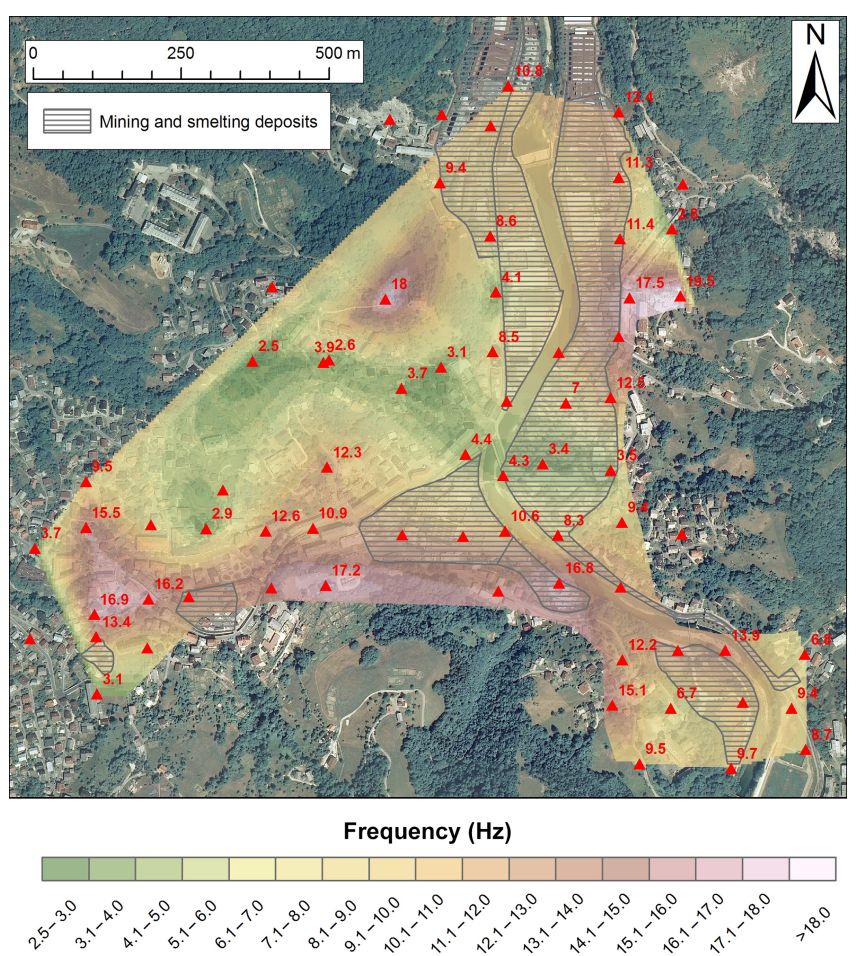

Figure 8. Map of the sediments main resonance frequency in the Idrija town area derived from microtremor measurements. Triangles indicate points of all measurements. Corresponding labels indicate the resonance frequency for locations with sufficient HVSR response. Basemap is digital orthophoto image (Surveying and Mapping Authority of the Republic of Slovenia).

sonry buildings was surveyed with the microtremor method in five Slovenian towns (Gosar, 2012) to derive main building frequencies. The statistical analysis of these results versus the number of floors was performed to generalize the identification of potential soil-structure resonance. Taking into account that two- and three-floor masonry buildings prevail in Slovenian towns, their frequency range was established at 5.6-11.1 Hz. The possible occurrence of soil-structure resonance should therefore be sought, especially in this frequency range, in Idrija as well, where similar buildings prevail. From the isofrequency map shown in Fig. 8 it is clear that the $5.6-11.1 \mathrm{~Hz}$ frequency range occupies a large part of the surveyed town area. Soil-structure resonance could therefore be a serious issue in Idrija. This should be further investigated by microtremor measurements within individual buildings and a direct comparison of the results with free-field data. To generalize the results to a characteristic set of buildings, it would be necessary to establish relations between the buildings' heights and their fundamental frequencies (longitudinal and transversal). While several such investigations were recently performed in Europe for reinforced-concrete buildings (e.g. Gallipoli et al., 2010), there is still lack of such studies for masonry buildings, which prevail in Idrija. 

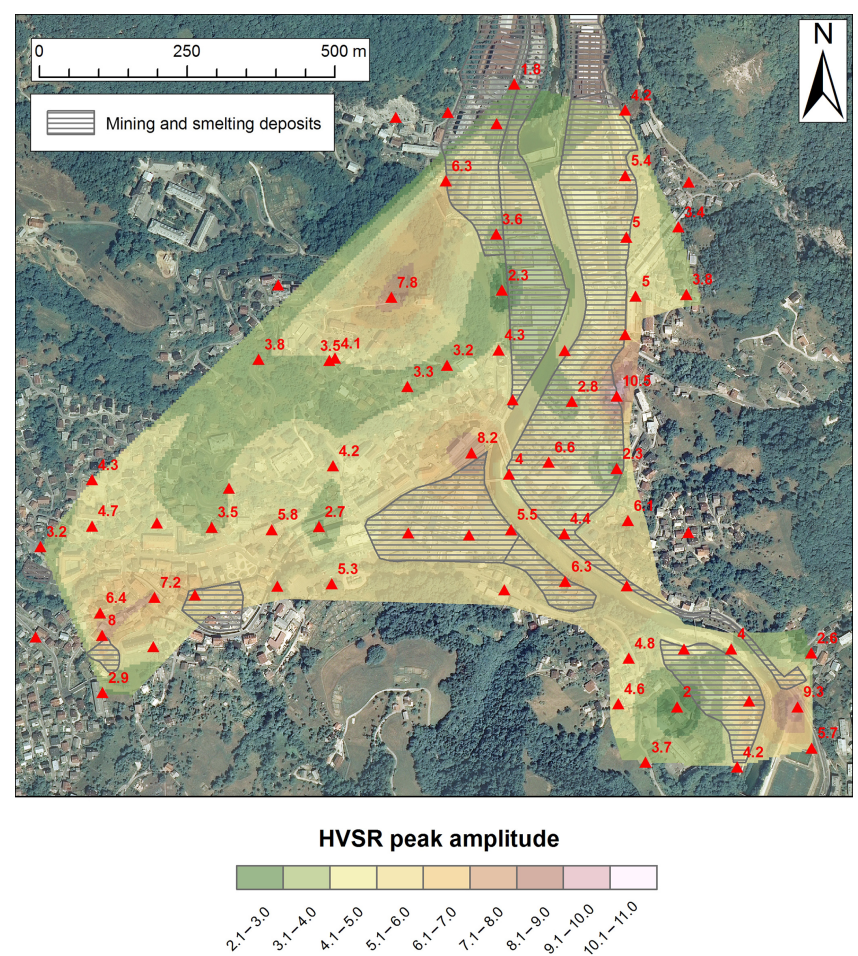

Figure 9. Map of microtremor HVSR peak amplitudes in the Idrija town area. Triangles indicate points of all measurements. Corresponding labels indicate the peak amplitudes for locations with sufficient HVSR response. Basemap is digital orthophoto image.

However, the first step was to prepare the free-field frequency map to support further soil-structure resonance analyses.

Another application of the derived isofrequency map is to support soil classification, because recent investigations (Luzi et al., 2011) have shown that the fundamental frequency of sediments can be used with the average S-wave velocity to improve classifications according to different building codes. However, not many examples of such an application of microtremor HVSR results have been published so far.

\section{Conclusions}

Microtremor HVSR investigations performed in the Idrija area have shown that this method is applicable to support seismic microzonation in the given geological conditions. The main results of the study are the isofrequency and HVSR peak amplitude maps of the soft sediments. Although a part of the town is built on alluvial sediments of the Nikova and Idrijca rivers and on artificial mining and smelting deposits accumulated through centuries of mining activity, there is no clear correlation between the extent and the supposed thickness of sediments and the distribution of resonance frequencies or HVSR peak amplitudes. This can be explained by a rather complex and uneven geometry of sediments or de- posits and the different levels of compaction (stiffness). At approximately one third of all measured locations it was impossible to derive the resonance frequency because of flat or nearly flat HVSR curves. This is certainly not a drawback of the microtremor method because a flat HVSR curve indicates a small or negligible impedance contrast between the sediments and the "seismological" bedrock and thus no amplification of ground motion. On locations where the frequency and the peak HVSR amplitude were derived, the microtremor method could have advantages compared to numerical solutions based on geophysical investigations and/or drilling. In a complex geological setting a very large number of geophysical measurements are needed to obtain representative data. This can be very expensive and difficult to realize in densely built environments where the free space to conduct active seismic refraction or MASW geophysical measurements is very limited. Both methods are also very sensitive to the normally high levels of noise. In contrast, the microtremor method can be effectively applied even in conditions that are unfavorable for geophysical investigations. The study has shown that the microtremor HVSR method is successful in a complex geological setting and thus represents an important validation of the methodology. This result is of wider scientific interest, especially because most of the published studies were performed on sedimentary basins of rather regular shape. Moreover, the recommended alternative investigations of the velocity structure using more expensive methods could be more efficiently planned if they were based on the microtremor HVSR results. However, microtremor investigations are only one step in a complete microzonation study that leads to the definitions of site-specific response spectra used in earthquake engineering.

The sediments' main resonance frequency $\left(f_{0}\right)$ derived from the microtremor HVSR measurements has three basic applications in seismic microzonation. Firstly, it can be used with data on the buildings' fundamental frequencies to assess the possible occurrence of soil-structure resonance (e.g. Gallipoli et al., 2004; Gosar, 2012). Secondly, it can be a complement to the average S-wave velocity in the upper $30 \mathrm{~m}\left(V_{s, 30}\right)$ as proposed by Ansal (2004) and Luzi et al. (2011). Most of the seismic codes make use of the $V_{s, 30}$ to discriminate soil categories, although some doubts exist about the capability of $V_{s, 30}$ to predict the actual amplification of sediments. Luzi et al. (2011) showed that the standard deviation associated with ground motion prediction is significantly reduced when the classification is based on the couple of variables $V_{s, 30^{-}}$ $f_{0}$. Finally, the resonance frequency is useful in calibrating the $V_{s}$ profile, which can be uncertain even when the microtremor array or the MASW measurements are conducted. This can be achieved by the application of joint modeling of the HVSR and dispersion curves (Micromed, 2008). However, these issues need further investigations. Any successful application of the microtremor HVSR method in complex conditions similar to the ones in Idrija is a valuable scientific contribution. In Idrija all three applications are feasible 
because a high-level quantitative microzonation is acutely needed in the future, as is a direct analysis of the danger of soil-structure resonance for individual buildings, including the cultural heritage mining structures protected by UNESCO, in order to protect them from the earthquake hazard.

Data availability. The database of microtremor measurements is available at http://www.arso.gov.si/Idrija_MicrotremorHVSR/ (Gosar, 2017).

Competing interests. The author declares that he has no conflict of interest.

Acknowledgements. The study was realized with the support of the research program P1-0011 financed by the Slovenian Research Agency.

Edited by: Filippos Vallianatos

Reviewed by: two anonymous referees

\section{References}

Ansal, A.: Recent advances in earthquake geotechnical engineering and microzonation, Kluwer Academic Publishers, Dordrecht, 354 pp., 2004.

Bard, P. Y.: Microtremor measurements: a tool for site effect estimation?, in: The Effects of Surface Geology on Seismic Motion, edited by: Irikura, K., Kudo, K., Okada, H., and Sasatami, T., Balkema, Rotterdam, 1251-1279, 1999.

Bonnefoy-Claudet, S., Cornou, C., Bard, P. Y., Cotton, F., Moczo, P., Kristek, J., and Fäh, D.: H / V ratio: a tool for site effects evaluation. Results from 1-D noise simulations, Geophys. J. Int., 167, 827-837, 2006.

Boutin, C. and Hans, S.: How far ambient noise measurement may help to assess building vulnerability?, in: Increasing seismic safety by combining engineering technologies and seismological data, edited by: Mucciarelli, M., Herak, M., and Cassidy, J., Springer, 151-180, 2008.

Bramerini, F., Castenetto, S., and Naso, G.: Guidelines for Seismic Microzonation. Conference of Regions and Autonomous Provinces of Italy - Civil Protection Department, Rome, 120 pp., 2015.

Čar, J.: Geological structure of the Idrija-Cerkno hills, Explanatory book to the Geological map of the Idrija-Cerkno hills between Stopnik and Rovte in scale $1: 25.000$, Geological Survey of Slovenia, Ljubljana, 127 pp., 2010.

Čar, J. and Gosar, A.: Idrija fault and displacements along it, Idrijski razgledi, 16, 105-118, 2011.

Chatelain, J. L., Guillier, B., Cara, F., Duval, A. M., Atakan, K., and Bard, P. Y.: Evaluation of the influence of experimental conditions on $\mathrm{H} / \mathrm{V}$ results from ambient noise recordings, B. Earthq. Eng., 6, 33-74, 2008.

Fitzko, F., Suhadolc, P., Aoudia, A., and Panza, G. F.: Constraints on the location and mechanism of the 1511 Western Slovenia earthquake from active tectonics and modelling of macroseismic data, Tectonophysics, 404, 77-90, 2005.

Gallipoli, M. R., Mucciarelli, M., Castro, R. R., Monachesi, G., and Contri, P.: Structure, soil-structure response and effects of damage based on observations of horizontal-to-vertical spectral ratios of microtremors, Soil. Dyn. Earthq. Eng., 24, 487-495, 2004.

Gallipoli, M. R., Mucciarelli, M., Šket Motnikar, B., Zupančič, P., Gosar, A., Prevolnik, S., Herak, M., Stipčević, J., Herak, D., Milutinović, Z., and Olumćeva, T.: Empirical estimates of dynamic parameters on a large set of European buildings, B. Earthq. Eng., 8, 593-607, 2010.

Gosar, A.: Determination of masonry building fundamental frequencies in five Slovenian towns by microtremor excitation and implications for seismic risk assessment, Nat. Hazards, 62, 1059-1079, 2012.

Gosar, A.: The database of microtremor measurements in the town of Idija, available at: http://www.arso.gov.si/Idrija_ MicrotremorHVSR/, last access: 16 June 2017.

Gosar, A., Rošer, J., Šket Motnikar, B., and Zupančič, P.: Microtremor study of site effects and soil-structure resonance in the city of Ljubljana (central Slovenia), B. Earthq. Eng., 8, 571-592, 2010.

Gosar, M. and Čar, J.: Influence of mercury ore roasting sites from 16 th and 17 th century on the mercury dispersion in surroundings of Idrija, Geologija, 49, 91-101, 2006.

Košir, M. and Cecić, I.: New findings on the 26 March 1511 earthquake, Idrijski razgledi, 56, 90-104, 2011.

Lapajne, J., Šket Motnikar, B., and Zupančič, P.: Design ground acceleration map of Slovenia, Potresi v letu, 1999, 40-49, 2001.

Luzi, L., Puglia, R., Pacor, F., Gallipoli, M. R., Bindi, D., and Mucciarelli, M.: Proposal for a soil classification based on parameters alternative or complementary to $V_{s, 30}$, B. Earthq. Eng., 9, 18771898, 2011.

Micromed: Tromino user manual, Micromed, Treviso, 2005.

Micromed: An introduction to the phase velocity spectra module in Grilla, Micromed, Treviso, 2008.

Mlakar, I. and Čar, J.: Geological map of the Idrija-Cerkno hills between Stopnik and Rovte in scale $1: 25.000$, Geological Survey of Slovenia, Ljubljana, 2009.

Moulin, A., Benedetti, L., Gosar, A., Jamšek Rupnik, P., Rizza, M., Bourles, D., and Ritz, J.-F.: Determining the present-day kinematics of the Idrija fault (Slovenia) from airborne LiDAR topography, Tectonophysics, 628, 188-205, 2014.

Moulin, A., Benedetti, L., Rizza, M., Jamšek Rupnik, P., Gosar, A., Bourles, D., Keddadouche, K., Aumaitre, G., Arnold, M., Guillou, V., and Ritz, J.-F.: The Dinaric fault system: Largescale structure, rates of slip, and Plio-Pleistocene evolution of the transpressive northeastern boundary of the Adria microplate, Tectonics, 35, 2258-2292, 2016.

Mucciarelli, M. and Gallipoli, M. R.: A critical review of 10 years of microtremor HVSR technique, Boll. Geof. Teor. Appl., 42, 255-266, 2001.

Mucciarelli, M., Contri, P., Monachesi, G., Calvano, G., and Gallipoli, M. R.: An empirical method to assess the seismic vulnerability of existing buildings using the HVSR technique, Pure. Appl. Geophys., 158, 2635-2647, 2001.

Reiter, L.: Earthquake hazard analysis, Columbia University Press, New York, 253 pp., 1990. 
Ribarič, V.: Seismological map of Slovenia for 500 years return period, Seismological Society of Yugoslavia, Beograd, 1987.

SESAME: Guidelines for the implementation of the $\mathrm{H} / \mathrm{V}$ spectral ratio technique on ambient vibrations: measurements, processing and interpretation, available at: ftp://ftp.geo.uib.no/pub/seismo/SOFTWARE/SESAME/ USER-GUIDELINES/SESAME-HV-User-Guidelines.pdf (last access: 16 June 2017), 2004.
Šket Motnikar, B. and Zupančič, P.: Seismic intensity map of Slovenia, Ujma, 25, 226-231, 2011.

Živčić, M., Čarman, M., Gosar, A., Jesenko, T., and Zupančič, P.: Earthquakes in the area of the Idrija fault, Idrijski razgledi, 56, 119-126, 2011. 